\title{
Shifting voices with participant roles: Voice qualities and speech registers in Mesoamerica
}

\author{
M A R K A. S I C O L I \\ Max Planck Institute for Psycholinguistics, Postbus 310 \\ 6500 AH Nijmegen, The Netherlands \\ mark.sicoli@mpi.nl
}

A B S T R A C T

\begin{abstract}
Although an increasing number of sociolinguistic researchers consider functions of voice qualities as stylistic features, few studies consider cases where voice qualities serve as the primary signs of speech registers. This article addresses this gap through the presentation of a case study of Lachixío Zapotec speech registers indexed though falsetto, breathy, creaky, modal, and whispered voice qualities. I describe the system of contrastive speech registers in Lachixío Zapotec and then track a speaker on a single evening where she switches between three of these registers. Analyzing line-by-line conversational structure I show both obligatory and creative shifts between registers that co-occur with shifts in the participant structures of the situated social interactions. I then examine similar uses of voice qualities in other Zapotec languages and in the two unrelated language families Nahuatl and Mayan to suggest the possibility that such voice registers are a feature of the Mesoamerican culture area. (Voice quality, register, performance, metapragmatics, Mesoamerica, Zapotecan, Mayan, Nahuatl)*
\end{abstract}

\section{N T R O D U C T I O N}

Mary, an indigenous Zapotec woman from southern Mexico, speaks in several voices during a day. To different people and for different social purposes she may use falsetto, breathy, whispered, creaky, or modal voice. Falsetto voice shows respect to her godparents and other ritual kin, and is the voice used in prayers. Important messages and instructions are whispered. Breathy voice drives animals, scolds children, and demands confirmation from another participant. Through creaky voice she seeks commiseration from her conversational partner. Her voice quality is shifted at different times both to assume situated social roles and to emblematically recognize the social categories present to a speech event. She also knows strategies for navigating and avoiding the voices required of her by some participant roles.

Although an increasing number of sociolinguistic researchers consider functions of voice qualities as stylistic features, few studies consider cases where voice 
qualities serve as the primary signs of speech registers. This article addresses this gap through the presentation of a case study of Lachixío Zapotec speech registers indexed though falsetto, breathy, creaky, modal, and whispered voice qualities. I aim to show that it would benefit sociolinguistics to consider the intersection of two concepts referred to as REGISTER in two separate literatures: LINGUISTIC REGISTERS and PROSODIC REGISTERS, and that by examining the concepts of voice and register together, we gain a more nuanced understanding of the human voice in culture and society. Linguistic registers have been defined as linguistic REPERTOIRES that co-occur with particular social practices and social persons (Agha 2004). Prosodic registers refer to a pitch level or phonational setting across an utterance (Laver 1980). Pitch registers define a range of pitch within which an utterance is cast. The whole utterance can have a higher or lower mean pitch value than another utterance. The term phonational register captures the fact that an utterance can be cast in one of several voice qualities, like falsetto, breathy, creaky, modal, whisper, or a number of functional combinations of these phonations. When voice quality is the primary linguistic cue for a register, I refer to this subtype of speech register as a VOICE REGISTER.

The study of voice registers is a study of voice qualities that become enregistered and maintained through their co-occurrence with speech situations and participation roles. While pitch and phonations also function across multiple other levels of language ranging from segments and words to phrases and messages, the use of pitch and phonation in a voice register relates to its use by a participant in assuming a social role within a participation framework. While participant roles are present in all speech events, some of the transcripts of audio and video recordings in this paper show the well-defined social structure of Zapotec kin and ritual kin relationships. This highlights a potential conflict between a speaker's ritual rights and responsibilities in a socially structured speech event and the role they must assume to move a dialogue forward. Speakers negotiate responsibilities to the kin relations while also assuming roles like speaker and addressee to animate and receive speech.

The cuing of speech registers through the nonreferential acoustics of phonation and pitch brings to the fore a contrast with LEXICAL REGISTERS, which cue different levels of speech primarily through morpho-lexical segments with referential functions. A shift in voice quality can function similarly to a lexical shift. For example, the Lachixío pronoun system does not differentiate between respectful and familiar address through second-person pronoun reference. Falsetto voice quality is used in Lachixío where we might find formal pronouns marking a respect register in some other languages. A crucial difference between these two strategies is that the voice register is indicated separately and independently from the referential system of a language, which has potentials and consequences that are distinct from lexical registers. Lexical marking makes use of semiotic material that is necessarily referential, but prosodic marking makes use of nonreferential material to frame words by becoming a part of them. 
This article considers the semiotic range of social functions that voice registers play for speakers in a Zapotec community of Oaxaca, Mexico. I describe the system of contrastive voice registers for Lachixío Zapotec, which is spoken in a mountain forest of southwestern Oaxaca by about 4,000 speakers in and around the towns of Santa María and San Vicente Lachixío. The people live through a combination of subsistence agriculture, community-organized logging, emigration to other regions of Mexico and the United States as wage laborers, and more recently, through a limited number of local entrepreneurial ventures. Speakers of Lachixío use different prosodic registers to frame speech and social actions.

Falsetto voice is a phonation characterized by high tension throughout the larynx and a stretching and thinning of the vocal folds (Laver 1980:118). It is associated with high pitch and is often accompanied by lower intensity than modal voice. High-pitched voice is used when addressing God in prayer to show respect and it is also the voice that is used when addressing deceased relatives (Sicoli 2007). Persons 1997 and Sicoli 2007 agree that among people who interact face-to-face, high-pitched voice is used when speaking with elders. It is used with ritual kin, where it is common to address one's godparent (tòo mballe) in high-pitched voice without expecting the same in return (a non-reciprocal use). Between mballe (compadres or coparents), high-pitched voice is used reciprocally, each interlocutor marking respect for the other with the high-pitched voice register. It is also used when talking to elected members of the town government (Persons 1997), but this seems to be falling out of use in Lachixío (Sicoli 2007).

Breathy voice is a phonation characterized by a looseness and aperiodic vibration of the vocal folds often with slight audible friction (Laver 1980:132). Ladefoged described the vocal folds as "flapping in the breeze" during its articulation (Pam Beddor, p.c. 2006). It is generally associated with low pitch. In Lachixío, breathy voice is used in strong assertions, imperatives, and requests for confirmation. It can also be used in the driving of animals where it becomes a harshbreathy voice.

Whispered voice is a phonation characterized by a triangular opening of the glottis with low adductive tension and moderate to high medial compression (Laver 1980:120). Whisper can combine with modal voice to produce a quality of whispery voice. In Lachixío whisper functions for important instruction to children and close kin, and to exclude participants other than the intended addressee. It often combines with gaze in achieving this restricted participation frame.

Creaky voice is a phonation characterized by strong adductive tension, medial compression, and low airflow, resulting in a low-frequency tapping sound (Laver 1980:126). This sounds much like an old hinge needing oil (hence the name). It is used in Lachixío to seek commiseration from someone.

All of the above-mentioned phonations also contrast with modal voice, the voice quality characterized by periodic vibration along the full lengths of the vocal folds.

I illustrate these features through transcripts of conversational data on which I have undertaken acoustic analysis, and support my interpretations of the voice 
qualities by referring to PARTICIPANT ROLES (Goffman 1974, 1981) and SPEECH SITUATIONS (Hymes 1974) that co-occur with the shifts in voice qualities, and by drawing on ethnographic dialogues where native speakers have reflected upon the social actions and contextual features that make voice qualities an important part of the linguistic array in Lachixío.

In this article, I first review the literature on voice quality and speech registers, presenting theory from linguistics, ethnography of communication, and conversation analysis. I present the case study of Lachixío, describing a system of voice registers, and then track a single speaker on a single evening as she obligatorily and creatively shifts between different phonations to define her roles in the interaction structures. I make several comparisons with other languages, first noting several unpublished reports of similar uses of voice quality in other Zapotec languages, and then, drawing upon published and unpublished reports of other unrelated language families of Mesoamerica, I consider that voice registers may be a discursive feature of the Mesoamerican cultural area.

\section{O I C E Q A L ITIES}

The literature on voice qualities represents a diversity of interests in the social sciences and humanities. Over the last century, scholars of various disciplinary affiliations have contributed investigations in areas such as linguistics, anthropology, psychiatry, and psychology. Important foundational scholarship on the phonetics of voice qualities is found in Catford 1964, Laver 1980, and Gordon \& Ladefoged 2001. Catford 1964 surveys laryngeal settings, giving acoustic and physiological descriptions of falsetto voice, breathy voice, whispery voice, and more complex articulations like whispery creak, voiced creak, and a whisperyvoiced creak. He describes what he calls "nonphonological" functions for voice qualities that are directly related to the situation of speech, indicating such categories as the speaker's sex, age, health, social class, and place of origin (Catford 1964). Laver has written extensively on the articulation of voice quality, providing us with fundamental descriptions of basic analytical concepts and descriptions of the laryngeal settings involved in the production of voice qualities that he referred to as REGISTERS, occurring across an utterance in similar way that PITCH REGISTERS have been described in intonational phonology (Ladd 2008, Laver 1980, 1991). In addition to his phonetic work on articulation, Laver (1968) describes voice qualities as indexical signs and as a site for the investigation of the folk labeling or metalanguage of voice qualities. He describes a number of complex combinations of voice qualities that have impressionistic labels in British English: voices like Ginny, Husky, Gruff, and Golden.

In a much earlier consideration of voice quality, Edward Sapir's 1927 essay, "Speech as a personality trait," calls for the analyses of speech features like voice qualities. He writes that the "analysis would take up the different levels of speech, starting from the lowest level, which is the voice itself, clear up to the 
formation of complete sentences" (reprinted in Mandelbaum 1949:533). Sapir develops a view of simultaneous or "superimposed" functions in speech, which he discusses in terms of "levels." Sapir identifies four levels: voice, voice dynamics, pronunciation, and vocabulary. ${ }^{1}$ Most work on sociolinguistic variation has been at the levels of pronunciation and vocabulary (for a review of sociophonetic attention to pronunciation see Hay \& Drager 2007).

While there has been only a limited and sporadic interest in the sociolinguistics of voice qualities in linguistics and ethnography (for important contributions see Bourdieu 1991, Caton 1986, Gaudio 1994, Graddol and Swann 1989, Hall 1995, Hill 1995, Hymes 1983, Irvine 1974, Lakoff 1975, Tannen 1993, and Tedlock 1983), the last decade has been characterized by an increase in the number of scholars systematically focusing on voice qualities as sign vehicles for sociolinguistic signification. Mendoza-Denton (1997, 2007), for example, describes the use of creaky voice as a sign of a gang girl persona in a central California high school. She also shows creaky voice picked up to trope this persona by a speaker expressing a stance of alignment toward another speaker (1999). Podesva $(2006,2007)$ analyzes the use of falsetto voice in gay male speech as a stylistic feature that builds its sociolinguistic meaning in the recruitment of ideologies of expressivity and masculinity. He shows the importance of voice quality as a resource for managing an individual's shifting position in a dynamic social world. Other developing work that analyzes the sociolinguistics of voice qualities and social identities include Starr (2007), who explores the voice quality that characterizes a feminine style in Japanese voice-overs, and Lefkowitz and Sicoli (2007), who consider creaky voice in the construction of gender and authority in American English. Each of these researchers examines the construction of social personae by bringing together acoustic analysis of voice qualities with ethnographic methods.

Discourse and conversation analysts have also shown some attention to voice qualities generally placing a more specific focus on intonation for which CouperKuhlen's (2003) review provides a helpful summary. Different work is characterized by varied levels of granularity - sometimes broadly qualifying lines of transcripts with notes that provide ethno-referential terms like Laver's "husky" quality or actions like "funny" or "whiny." However, some researchers give more detailed prose descriptions that relate abstract voice qualities like high pitch or nasality to the framing of actions in a speech event. In several cases Deborah Tannen attends specifically to voice qualities and other prosodic features as inviting particular frames for the interpretation of turns at talk. For example, she shows that features like lengthened vowels, high-pitched voice, and nasality frame an interjection as an act of teasing (1993:215). Central to Tannen's work has been the bringing of multiple voices to a speech event $(1989,1993)$, a practice that in her recent plenary address at the 2010 LSA meeting she referred to as the "taking on of voices," where speakers use shifts in prosody and morphosyntax to frame their utterances as dialogue - that is, to indicate that they are speaking in the voice of another person or even a nonverbal child or pet. All of these researchers 
demonstrate that voice qualities and other prosodic features can frame speech for action type, genre, or persona. It is certainly clearly established that the study of voice quality is crucial to the study of metapragmatics in conversation and discourse analysis. However, even with the recent increase in activity to develop our theory of the relationships between voice qualities and social indexicalities, we are still far from the goal that Eckert and McConnell-Ginet (2003:63) challenged five years ago of being able to talk about suprasegmentals as confidently as we talk about segmentals. My analysis of the voice qualities of Lachixío Zapotec speech develops this trajectory of research by bringing the discussion of prosodic register into a necessary dialogue with linguistic registers and processes of ENREGISTERMENT, thus hopefully revealing the potential for a more structured analysis of the human voice within social and linguistic theory.

\section{S P E E C H R E G I S T E R S}

The concept of speech registers also has a long history in the study of discourse and of social interaction. Atkinson and Biber review the literature and use register as a cover term for studies of register, genre, style, and text type. They state that the principle that unites these concepts as register phenomena is that they refer to language varieties associated with "particular situational or use characteristics" such that there are co-occurrence patterns between features of language variation and features of use or situation (1994:351). Atkinson and Biber delimit register studies to deal with actual discourse, with formal characteristics of language varieties rather than individual styles, and with the functional and conventional relationships between form and situation (1994:352). Most of the studies of register reviewed by Atkinson and Biber consider written language, which is in part a consequence of the prevalence for using written or transcribed corpora as the basis for analyis. Studies of spoken registers are often placed in juxtaposition with written registers (see e.g. Biber \& Hared 1994, Kim \& Biber 1994). Data for "spoken" discourse are often written transcripts, for which our analytical ground is constrained to the targets and conventions of transcription. It is not surprising that written genres have heavily influenced the studies of registers of spoken language. Spoken registers are most often characterized with reference to the linguistic patterns commonly represented in written forms - for example, features like lexical substitutions, morphological marking, word length, greater presence of relative clauses, and tense marking. Where the sound of a register is considered, it is generally at the level of the phoneme or of stereotypical intonation contours associated with questions - both features commonly represented in written language, and used in slightly broader contexts in conversational transcripts, such as the use of a question mark for rising intonation even with declarative function. Here, for example, important observations have been highlighted, such as the use of question intonation in declarative contexts in "women's speech" (Lakoff 1975:53), or in performing a sororitygirl identity (McLemore 1991). We see a clear projection from literacy to speech 
where Lakoff characterizes women's speech by writing that "women speak in italics" (1975:56). What, we should wonder, are the phonetic qualities of italic speech?

In linguistic anthropology studies of register have come to stress the importance of considering registers through their social and historical processes of enregisterment (Agha 1998, 2004, 2005). Agha defines a linguistic register as "a linguistic repertoire that is associated, culture-internally, with particular social practices and with persons who engage in such practices" (2004:24). Irvine similarly defines a linguistic register as "a coherent complex of linguistic features linked to a situation of use" (1990:127), which "draws on cultural images of persons" (1990:130). A focus on enregisterment brings to our focus the need to explain how registers become "differentiable from the rest of the language" (Agha 2004:24) or linked to particular social practices. The relationship between style and register then is one where styles become iconically representative of persons or practices: "every register involves co-occurence styles, some of which are assimilated into register models as enregistered styles" (Agha 2007:186). Registers are also creative of, and not simply reflective of social relations. Like early sociolinguistics, which correlated linguistic variables with categories like social class and gender as if these were always given before the speech situation, early register studies tended to uncritically assume the social categories with which a register co-occurs. Agha observes, rather, that "switching to the register may itself reconfigure the sense of occasion, indexically entailing or creating the perception that the social practice is now under way" (2004:25). Registers are part of the strategies with which speakers switch from one participation framework to another, drawing on stylized resources to assume stereotypical roles drawn out of sociohistorical experience.

One of the best-known examples of a register system is found in the Javanese speech levels described by Errington (1988), presented in Table 1. Speakers shift between three named registers: Ngoko, a low register; Madya; and Krama, a high register that takes much of its vocabulary from Indonesian. Errington notes that features of pronunciation can accompany the speech levels but that the most salient aspect of this system is the set of lexical substitutions.

TABLE 1. Javanese "language levels" or "speech styles" (Errington 1988:90).

\begin{tabular}{|c|c|c|c|c|c|}
\hline KRAMA & $\begin{array}{l}\text { 1. menapa } \\
\text { 2. menapa }\end{array}$ & $\begin{array}{l}\text { nandalem } \\
\text { panjenengan }\end{array}$ & $\begin{array}{l}\text { mundhut } \\
\text { mendhet }\end{array}$ & $\begin{array}{l}\text { sekul } \\
\text { sekul }\end{array}$ & $\begin{array}{l}\text { semanten } \\
\text { semanten }\end{array}$ \\
\hline MADYA & $\begin{array}{l}\text { 3. napa } \\
\text { 4. napa }\end{array}$ & $\begin{array}{l}\text { sampéyan } \\
\text { sampéyan }\end{array}$ & $\begin{array}{l}\text { mendhet } \\
\text { njupuk }\end{array}$ & $\begin{array}{l}\text { sekul } \\
\text { sega }\end{array}$ & $\begin{array}{l}\text { semonten } \\
\text { semonten }\end{array}$ \\
\hline NGOKO & $\begin{array}{l}\text { 5. apa } \\
\text { 6. apa }\end{array}$ & $\begin{array}{l}\text { sliramu } \\
\text { kowé }\end{array}$ & $\begin{array}{l}\text { mundhut } \\
\text { njupuk }\end{array}$ & $\begin{array}{l}\text { sega } \\
\text { sega }\end{array}$ & $\begin{array}{l}\text { semono } \\
\text { semono }\end{array}$ \\
\hline Gloss & Question-marker & you & take & rice & that much \\
\hline Translation & \multicolumn{5}{|c|}{ 'Did you take that much rice?' } \\
\hline
\end{tabular}


While it is by and large acknowledged that sound (segmental phonology or prosody) can be part of the array of signs that co-occur around the use of a linguistic register, lexical or morphological material is generally assumed to be criterial, as a public sign in co-occurrence with a social situation. Agha writes that "the occurrence of honorific lexemes is generally criterial for identifying honorific discourse, i.e., for identifying a segment of discourse as honorific in character" (1998:153). The focus on lexeme may be appropriate for some systems. However, it may also be a historical outcome of the dominant ways that speech registers have been discussed - through lexical substitutions, such as Javanese speech levels, or the well-known second person pronoun substitutions of European languages (Brown \& Gilman 1960, Paulston 1976). It may also be in part that lexical priority is rooted in the higher metalinguistic awareness of referential lexemes relative to nonreferential signs like prosody (Silverstein 1981). When ethnographic consultants characterize a register, they are likely to talk about the vocabulary that co-occurs rather than some prosodic or subphonemic feature. The nonreferential prosodies and especially the voice qualities associated with registers often lie below a threshold of conscious reflection for both consultants and researchers. ${ }^{2}$

Given these difficulties in talking about registers apart from morpholexical features, it is important to note that some ethnographic accounts have indeed shined an analytical light directly on prosodic qualities as critical to the understanding of speech registers. Irvine describes that rural Wolof speakers could "rely exclusively on prosodic contrasts to create register differences (Irvine 1998:55). Irvine's description of Wolof greetings (1974) discusses strategies of status manipulation in ritualized dyadic exchanges in a highly ranked caste society. She analyzes two levels of strategies split between the segmental and prosodic levels of the language. In Wolof ritual greetings, status is emergent in ones place in the sequence of turns taken in a greeting exchange. Relative status is expressed by who is the initiator of the greeting and who is the responder-it is the obligation of a lower-ranked individual to initiate the sequence. There is some flexibility here: where a slave talks to a noble, or a youth to an elder, the roles clearly align with social expectations; however, a noble may choose to lower himself by initiating a greeting to someone of lesser rank to mark the exchange as special.

The roles expressed in the turn-taking system are not necessarily reflective of a person's actual position in the society. Irvine describes prosody as another level of semiotic coding that always accompanies the turns of talk in the greeting exchange. In Wolof society, lower-ranked castes (epitomized in the griot) are indexed by speech that is high pitch, high volume, and rapid tempo. Noble speech is, on the contrary, low pitch, low volume, and slow tempo. These prosodic speech styles are superimposed on the turn-taking structure of the greeting sequences. Through prosodic marking a speaker "may emphasize the claim to higher or lower status indicated by his greeting role; or he may indicate that ... he does not really belong in the status in which he finds himself" (Irvine 1974:183). In the words of Sapir "one may express on one level of patterning, what one will not or 
cannot express on another" (Mandelbaum 1949:543). Because the speech styles are relative to each other (high-low, loud-quiet, fast-slow) the prosodies become important in defining relative rank within a caste. A young noble may use lowcaste style when talking to an older noble, but high-caste style when talking to a griot. Here the caste difference between griot and noble is enregistered as a relative index of status within a caste. Irvine draws attention in this early work to some of the fundamental issues of prosodic style, style shifting, and the deployment of speech registers in creating personae and negotiating social roles.

Caton (1986:302) also draws attention to prosodic and phonational qualities of ritual greetings in Yemen. He writes:

adult male tribesmen often use creaky voice and a high tenor, almost a falsetto in pronouncing the greetings, which might be interpreted as a stylized way of rendering "manhood" and "virility." Loudness or force is also an important feature of the performance. By contrast, the voice of the sayyid is more "natural" and softer, sometimes even trailing off into a barely audible whisper. These differences in voice quality iconically index the "aggressive" and "warlike" person as opposed to the man of "quiet contemplation" and "peace."

Attending to voice qualities like these, we have come to know that any feature co-occurring with actions of speech can be promoted through processes of iconization and indexicality to function as indicators of a speech register. Thus Tedlock (1983:54) stated that it is at the level of semantic function that the arbitrary wall between "linguistics" and "paralinguistics" collapses. In all of these cases we see that voice quality can indicate a meaningful shift in register just as lexical material can.

In the Lachixío Zapotec registers that are the topic of the next section, the array of linguistic features that indicate a speech register are phonations and pitch levels that occur over turns of talk. Lexical markers are not necessarily present, so the semiotic burden that indicates the register shift lies with the prosodic system-in HOW SOMETHING IS SAID, and not directly in WHAT IS SAID. In descriptions of languages it is our burden to also provide rich descriptions of the voices available to speakers. A shift in voice register is a shift to a speech style that has become a marker of social roles, group membership, or a participant role in a social interaction.

\section{OICE REGISTERS OF L ACHIXÍO Z A POTEC}

My most impressive memory from my first fieldtrip to Lachixío in 1997 is observing the range of voices into which a single person could shift. I had already been working with a single speaker for several weeks outside his hometown at a field station of the Project for the Documentation of the Languages of Meso-America, but the voice shifts were not something that emerged during such linguistic elicitations that were designed to collect lexical items from one person at a time, put them in written form, and describe their grammatical properties. I returned to Lachixío to 
conduct Ph.D. research (Sicoli 2007), investigating in part the range of pragmatic uses for voice qualities in narratives and conversations in face-to-face interactions. Conversation is the site for the emergence of voice registers in Lachixío, particularly interactions including speakers who embody certain social relationships to each other, to the message, or who are participating in certain types of speech events. In this section I will present transcribed data of audio and video recordings, interpreting the functions of the voices in these interactions based on ethnographic consultation with speakers about the original media. I will focus specifically on falsetto, breathy, and whispered voices. ${ }^{3}$

\section{Voices of respect and authority}

Respect and authority are conveyed through diagrammatic relationships where relatively higher pitch marks higher-ranked social relations and increasingly lower pitches convey greater authority or influence over another speaker (Sicoli 2007). The highest respect is indicated with high-pitched falsetto voice and the greatest authority with low-pitched breathy voice. ${ }^{4}$ Consider example (1) of the falsetto register. The transcript is of a dialogue that took place between a mother and daughter, who operate a small general store from their house, and Flavio, ${ }^{5}$ a customer who arrived to purchase some food items. The entire exchange was conducted in what is referred to locally as "respectful voice." The mother is older than Flavio, who is older than the daughter. Here all speakers are using the high-pitched voice register to show mutual respect with their speech. However, within the register Flavio uses different pitch heights to show graded levels of respect for his two addressees. The male speaker has different ritual responsibilities to the mother and daughter. In line 1, his greeting to the elder mother is marked for respect by being sequence-initial, in higher pitch, and by using the person reference item nisso 'aunt'. His peak pitch is markedly higher (nearly $50 \mathrm{~Hz}$ ) in line 1 than in line 3, where he addresses his greeting to the younger woman. To the elder woman's daughter it is still in a higher pitch than his unmarked voice, indicating gradient levels of respect. ${ }^{6}$

\begin{tabular}{|c|c|c|c|}
\hline 1 & Flavio: & $\begin{array}{l}\uparrow \uparrow \text { máa lò né nisso } \uparrow \\
\text { greetings } 2 \mathrm{~s} 3 \mathrm{AO} \text { aunt } \\
\text { 'Greetings Aunt.' }\end{array}$ & (facing the mother) \\
\hline 2 & Mother: & $\begin{array}{l}\uparrow \uparrow \text { kyèe né Flavio. } \uparrow \\
\text { come 3Ao Flavio } \\
\text { 'Come in Flavio.' }\end{array}$ & \\
\hline 3 & Flavio: & $\begin{array}{lll}\text { ^máa lò } & \text { né: } \uparrow \\
\text { greetings } & 2 \mathrm{~s} & 3 \mathrm{AO} \\
\text { 'Greetings.' } & \end{array}$ & (facing the daughter) \\
\hline & Daughter: & $\begin{array}{l}\uparrow \uparrow \text { kyèe né Flavio. } \uparrow \\
\text { come 3Ao Flavio } \\
\text { 'Come in Flavio.' }\end{array}$ & \\
\hline
\end{tabular}


The next sequence in the conversation was the business of buying goods between Flavio and the daughter that also took place with the participants using high pitch towards each other. The closing sequence in example (2) again shows Flavio using higher pitch when directed toward the mother (line 22) than to the daughter (line 24).

(2)

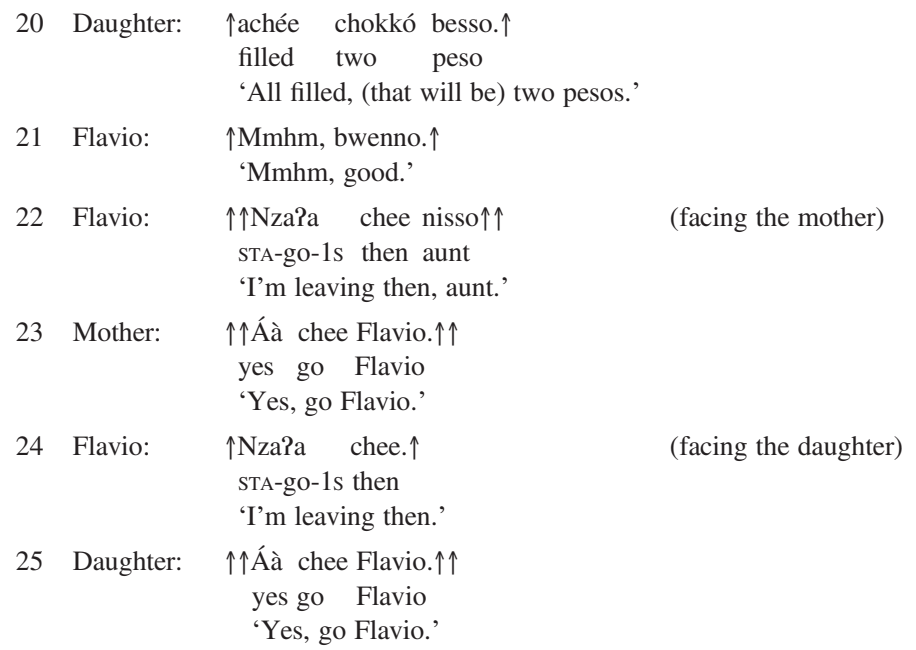

The potential to use a gradient high-pitch continuum within the respectful voice register becomes apparent in scenes like these where the pitch shifts co-occur with speech selecting two addressees in adjacency or near adjacency. The contrast between using the address term nisso 'aunt' (used with elder nonrelated persons as well as related kin) is also present, but such lexical marking is not a necessary feature for the high-pitched voice as in lines 3 and 24. Examples (1) and (2) show these relative pitch values in natural conversation.

Another speaker showed this gradient use of high pitch during an interview while we were discussing high-pitched voice. He produced several examples of high-pitched voice together, first imagining one addressee then a different one and then several others. In the interview setting, he was able to produce several respectful utterances in adjacency, which brought to the fore the notable pitch differences patterning with the different addressees he imagined. Table 2 presents these examples, with each example numbered in ascending order from the bottom of the table to the top. The numbers in the middle column represent the peak pitch of the utterance. The right column indicates the social role of the addressee to whom the utterance was directed. Within the table, example (3) shows an utterance that was directed toward an elder male. As the speaker himself is a respected elder, he does not raise his pitch beyond his normal voice. Example (4) was produced for an elder female. Here the speaker raised his pitch from the previous utterance showing that within this category he would stereotypically show respect across 
MARK SICOLI

TABLE 2. High pitch and social role.

\begin{tabular}{|c|c|c|c|}
\hline & Utterance & Peak Pitch & Social Role \\
\hline (7) & $\begin{array}{l}\text { NzaPa né tetta. } \\
\text { STA-go 1 Ao father } \\
\text { 'I'm going father.' }\end{array}$ & 282 & Father (deceased) \\
\hline (6) & $\begin{array}{l}\text { Nza?a né tòomballe. } \\
\text { STA-go 1AO godfather } \\
\text { 'Goodbye godfather.' }\end{array}$ & 280 & Godfather \\
\hline (5) & $\begin{array}{l}\text { Máa lò né mballe. } \\
\text { greeting 2s 1AO coparent } \\
\text { 'Greetings compadre.' }\end{array}$ & 260 & Compadre \\
\hline (4) & $\begin{array}{l}\text { Máa lò né nisso. } \\
\text { greeting 2s 1AO aunt } \\
\text { 'Greetings Aunt.' }\end{array}$ & 191 & Aunt (elder) \\
\hline (3) & $\begin{array}{l}\text { Máa lò né xeyyo. } \\
\text { greeting 2s 1 AO uncle } \\
\text { 'Greetings Uncle.' }\end{array}$ & 160 & Uncle (elder) [modal] \\
\hline
\end{tabular}

gender. In (5) the same speaker then used a yet higher pitch for a greeting issued to his compadre 'coparent,' to whom he is bound by religious and personal commitment. Example (6) was directed to his godfather, the highly respected ritual kinship relationship. When he addressed an utterance to his deceased father (example (7)) it was in a comparable pitch to the godfather example. While high-pitched voice is not used to address living parents, at death ones status changes and deceased are spoken to like other ancestors, gods, and God. These examples show a DIAGRAMmATIC ICONICITY (Mannheim 2001:102, Peirce [1902] 1955) where utterances to a specific addressee who mandates greater respect are in a correspondingly higher pitch. Utterances toward the deceased father and mother and utterances toward a godfather or godmother were given the highest pitch values. The reciprocal bond of compadrazgo, marked by the compadre relationship, forms a middle stratum. The pitch for a female elder was in a lower-pitch stratum, but still higher than the baseline, or modal, voice that was used for a male in the same age set. ${ }^{7}$

High pitch is used in Lachixío to take a respectful stance toward another speaker and can be used gradiently to show differential deference. In a similar way, low pitch expresses an authoritative stance, and lower pitches a greater degree of authority.

In the grammatical system of Lachixío Zapotec, low tone is used to indicate the imperative mood (Sicoli 2007:97). There is not a way through the segmental morphology in Lachixío to mark imperatives. Rather one can either inflect a verb for the potential mood or the completive aspect. The potential mood marks a speaker state of believing/wanting something to be in the future. The completive aspect marks an event state as completed. The potential acts as a weak imperative and the completive a stronger imperative. In both cases the force of the utterance is inferred from a 
speech act that sets up a match between the words and the world (Searle 1976), either by stating ones desire, or by describing the state of a world in which the desired action is complete. Low pitch exists as a resource to strengthen the force of these command forms, increasing a speaker's influence over the actions of another speaker, which I interpret to be a stance of authority because for the speech act to be felicitous, an authoritative relationship must be recognized (at least a transient one at the moment of speech).

Table 3 shows the gradient of imperative forms for Lachixío. For both the potential-based imperative and the completive-based imperative there exists a low-tone variant that increases the force of the command. Repeated commands can be given in an even lower pitch, such as $\downarrow$ okyè?e é $\downarrow$, which would be uttered if perhaps an earlier command had not been recognized. An even stronger command would be issued in breathy voice \#okye?e e\#.

These shifts from low pitch to breathy voice have parallels in the phonotactics of the language. Breathy voice also emerges in the Lachixío phonological system from low tone in morphophonological environments, where low tones "pile up" in adjacency. In example (8) the phonemic low tone is marked by /L/, phonetic low tone by grave accent.

\section{(8) $\quad / / \mathrm{e}=\mathrm{L}+\mathrm{koko}+\mathrm{L} / / \quad$ ek\#òkkò\# 'corn dough (masa)'}

Thus an equivalency exists in Lachixío phonology that equates low pitch and breathy voice as phonetic variants of the same phonological sign. A parallel pattern exists in the voice register system. Authoritative moments in narrative and dialogue are presented in low pitch; contrastively lower pitches are possible and increase the force; and finally, breathy voice can emerge to create yet greater authority. I turn now to exemplifying such discursive uses of low pitch and breathy phonation.

Example (9) illustrates a shift to low pitch used by the narrator of the story to construct the authoritative voice of an employer telling an employee that he was denying her request for an advance on her salary. Just prior to these two lines, the mother in the story went to her boss to ask for an advance on her paycheck. She wanted the money to buy a doll that her daughter had been pining for, so much that the daughter fell gravely ill. The narrator constructed a trope from the low pitch using the pitch to both show the authoritative relationship of the boss

TABLE 3. Lachixio gradient of imperative forms.

\begin{tabular}{lll}
\hline \hline Weak imperative & kyéPe é & 'That it may get washed' \\
Relatively stronger weak imperative & kyè?e é & 'Would (you) wash it?' \\
Strong imperative & okye?e é & 'It got washed.' \\
Relatively stronger strong imperative & okyè?e é & 'Wash it!' \\
Still relatively stronger imperative & $\downarrow$ okyè?e é $\downarrow$ & 'Wash it!!' \\
Really strong imperative & \#okyè?e é\# & 'WASH IT!!!' \\
\hline
\end{tabular}


to the employer, as well as the lack of concern of the employer, who in the narrative is constructed as a "city person" uninterested in the well-being of his indigenous worker.

(9)

1 Chékkye nìi beè benné enò jri?i zéPe rínna? loo (2.0)

then say PL person REL HAB-make 3DIS work LOC

'Then the people for whom she worked said to her,'

$2 \downarrow$ Lekka méllo e?kko=tzee nèé? $\downarrow$

none money moment now

'There isn't any money right now.'

Example (10) is of breathy voice. The man I was working with first gave several commands in modal voice to a child who was repeatedly interrupting us. Finally, in breathy voice, he got the effect he desired. The form of this utterance is a couplet, itself an authoritative poetic form in Mesoamerica (Haviland 1990). The first line of the couplet is in breathy voice. The second line is in modal voice and is a formulaic line used often in the socialization of children. Note that both lines end with exclamative marker $r a$. The greater force of the first line is achieved in the breathy phonation.

1 \#zxònna? chee nìi á ra\# stop then say 1s EXC

'Stop it then I told you'

2 nzo?kko? nóo niì benné ra

listen REL say people EXC

'Listen to what the people say!'

The data in examples (1) through (10) illustrate the two gradient pitch continua: one in which higher pitches show more respect and another in which lower pitches show more authority. Within the domain of showing respect, this opposition can be drawn upon to show greater degrees of respect, just as lower and lower pitches can exert greater degrees of authority. It is relevant here to draw the parallel to the use of prosody in Wolof to mark the relative status roles that I discussed above. The prosodic qualities of high-caste noble speech contrast with those of low-caste griot speech. Within each caste this opposition can be troped to construct relative degrees of status.

In Zapotec, voice qualities have formal relationships with pitch, for example, in (8) where breathy voice emerges from quantitatively increasing low-pitch specifications in the phonology. Voice shifts with discourse functions build off of this first-order phonological indexicality. Speakers go beyond the laryngeal limits of their modal pitch range by shifting to nonmodal phonations: falsetto phonation shows the greatest respect; breathy phonation shows the greatest authority. This is indeed why I refer to these registers as falsetto and breathy registers, for they 


\section{Breathy Voice $\leftarrow$ Low Pitch $\leftarrow \rightarrow$ High Pitch $\rightarrow$ Falsetto Voice Authority $\leftarrow \quad \rightarrow$ Respect}

FIGURE 1. Pitch and voice continuum.

are the epitome of respect and authority that can be shown by the quality of one's voice. This relationship is shown in Figure 1.

Before we move on, I will characterize two more uses of breathy voice in Lachixío that support my interpretation of breathy voice as marking an authoritative register of speech. Breathy voice is also found in Lachixío dialogue when a listening speaker takes up an authoritative stance that challenges another speaker's account. In a narrative dialogue in Lachixío a listener can support, or challenge, the speaker by repeating part or all of the last speaker's turn. Repeating a line (or part of a line) from a prior speaker and delivering it back in modal voice is a "back channel" cue in much of Mesoamerica to communicate that the addressee is listening (see Brody 1986, 1994, Brown, Le Guen, \& Sicoli 2009). But when a speaker's last line is repeated in breathy voice in Lachixío, it has a different pragmatic force. The breathy voiced repetition creates a challenge to the prior speaker-one that questions the authenticity of the account.

In example (11) the first speaker, Mariano, comes to the end of a point he was making about the history of his town. He makes the point that the site where the town of San Mateo Mixtepec stands was once the location where the people of San Miguel Mixtepec mined stone to make lime (calcium carbonate used for preparing the corn dough staple). David, the responding speaker, copies Mariano's text as a vehicle for David's breathy voice. More than a request for confirmation, this utterance has a stronger force as a command for confirmation, which is supported by the above facts about breathy voice in imperatives. The breathy-voiced repeat provokes Mariano to respond and affirm that what he said is true. Example (12) shows a similar pattern.

1 Mariano: iPyyo edettxe kye?

lime pueblo DEF

'lime of the pueblo'

ndokkwi laa nóó samatéo (1.3)

STA-remove already REL San Mateo

'removed from San Mateo' (1.3)

i?yyo edettxe kye?

lime pueblo DEF

'Lime of the pueblo.'

4 David: \#i?yyo edettxe kye?\#

lime pueblo DEF

'Lime of the pueblo?' 
5 Mariano: kwa

this

'It is so.'

(12)

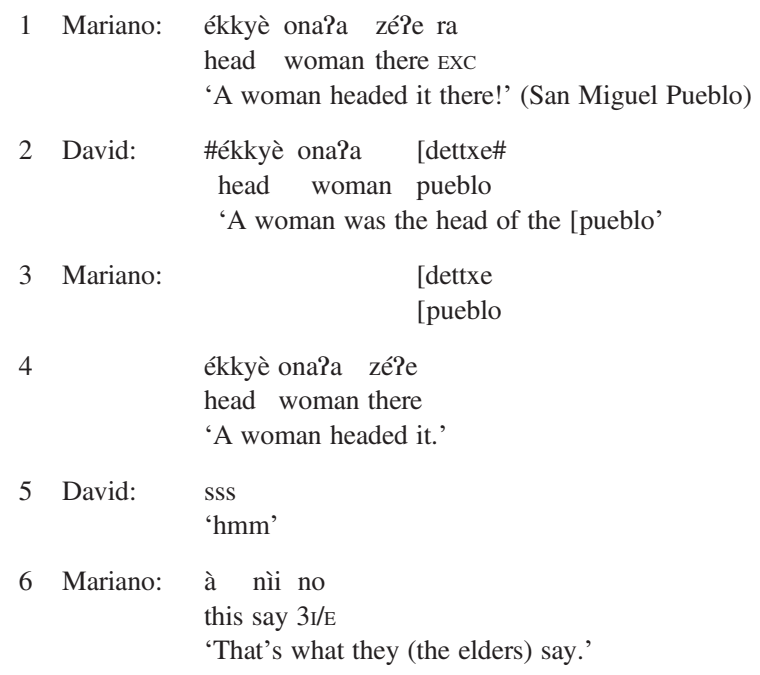

In example (12), David repeats Mariano's line referring to the time during the Mexican revolution when a woman was elected president of Mariano's town. David's repeat is again in a breathy voice. The other speaker had just introduced surprising information, given the gender roles that typically prevent women from filling positions in pueblo administration. As in the previous example, the breathy voice is treated as a request/demand for confirmation, provoking a sequence in which the initial speaker reaffirms his previous turn. Mariano repeats the information that was challenged, confirming his commitment to it. He further authenticates the information by attributing the story to the elders of the town, indicating them by a rarely used third-person pronoun of high respect, no.

\section{Shifting voice registers with participation roles}

In this section I follow Mary as she shifts between falsetto, modal, and whispered voice on a single occasion in which she and her husband are visiting neighbors. My purpose here is to track an individual speaker as she moves through several participation frameworks to illuminate the copatterning of voice qualities. The transcripts here are from a video recorded on the evening of July 2, 2009 in Santa María Lachixío. The setting is a kitchen house at about 9pm on the evening before the school graduation ceremonies. Mary and her husband (Husband-M) are visiting an elderly couple (Elder-f and Lencho) and their son (Son-L), daughter-in-law 
(Daughter-L), and grandsons (Boy1 and Boy2). Husband-M was the camera operator and I was not present in the scene. Mary has accompanied her husband while he records the video with this family, and then Mary and her husband are going to run errands. Many people in town are busy this night preparing for the school graduation ceremonies and the parties the following day. Elder-f is roasting chili peppers in a clay griddle over a wood fire to prepare a mole sauce for a party tomorrow to celebrate her grandson's (Boy2) middle school graduation.

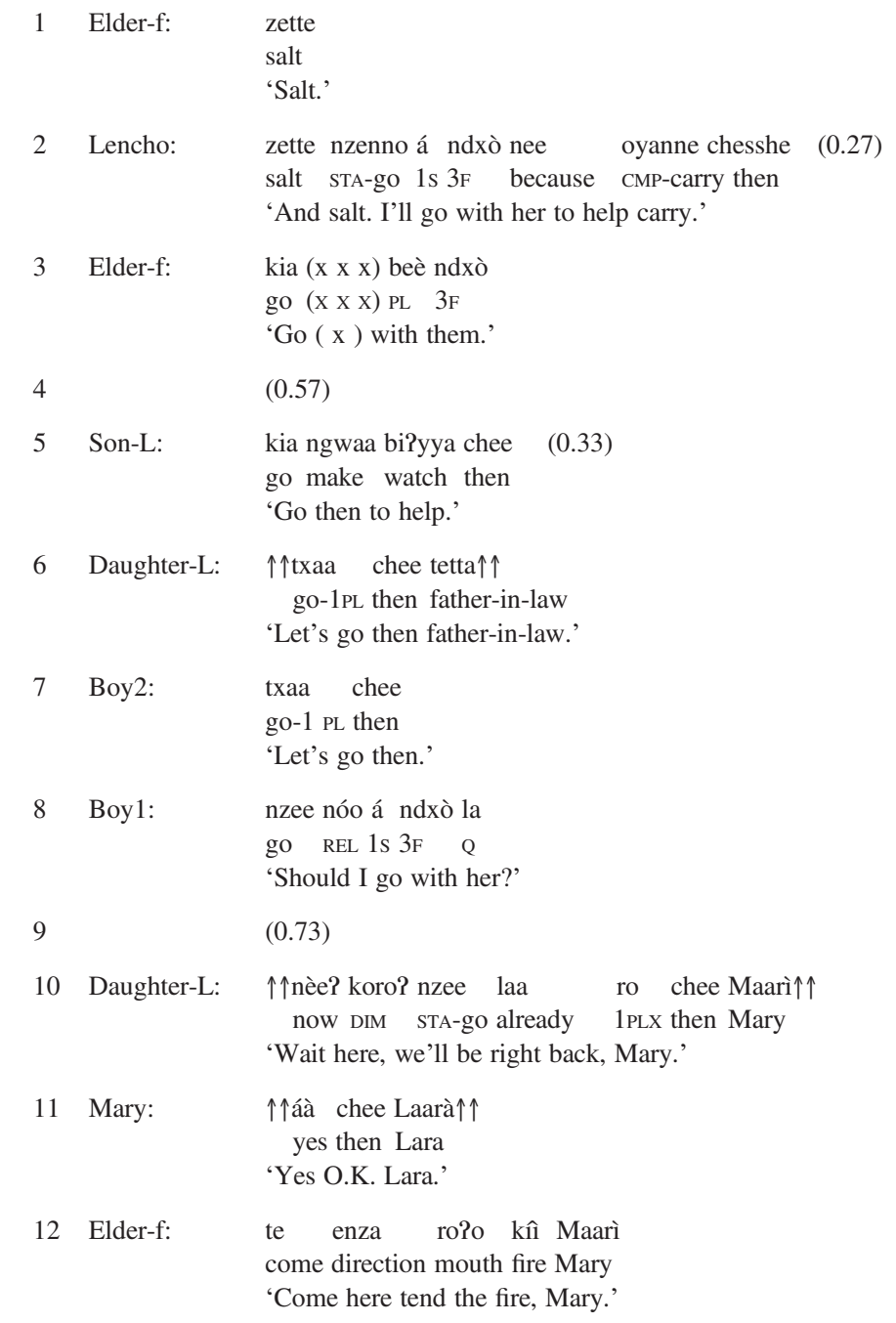




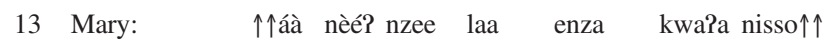
yes now STA-go already direction there aunt 'Yes, right away I'm coming, Aunt.'

14 Husband-M: kia enza ro?o kî biccha lò go direction mouth fire sun(heat) $2 \mathrm{~s}$ 'Go and tend the fire.'

15 Son-L: natze? xletta zokko ska? lò grab chair sit (?just) $2 \mathrm{~s}$ 'Take a chair with you.'

16 Mary: $\quad \uparrow$ áà $\uparrow$ yes 'Yes.'

17 (3.02) (Mary takes a chair and sits at the hearth.)

18 Husband-M: skwa? tzia kalla nóo mússika lekka like.this only NEG REL musician not.exist 'It's too bad we won't have musicians.'

19

20 Husband-M: stokko laa beè mússika lekka nekka Lencho another already PL musician not.exist STA-become Lencho 'Lencho was also saying we don't have musicians.'

21 Son-L: ni mússika lekka not.even musician not.exist 'Not even one.'

22 Mary: shi enza laa bisshà lò tòkko beè ì nii=kaa la how direction already call $2 \mathrm{~s}$ one $\mathrm{PL} \quad 3 \mathrm{M}$ say.already Q 'That's what I've been saying; Why don't you call just one of them?'

(.) (Mary looks to Elder-f)

23 Elder-f: [(Laughter)

24 Group: [(Laughter)

Earlier in this transcript a group (Daughter-L, Lencho, and the two boys) leaves to go to the store to buy salt and other items. Prior to this sequence, each interested party had announced some items that they thought should be bought at the store. In line 1 Elder-f states that she needs salt. Daughter-L is the one responsible for running the errand to the store, and her father-in-law, Lencho, and a couple of children accompany her. In line 6 Daughter-L uses falsetto voice to her father-in-law (an obligatory use of the respect register). She also uses falsetto when telling Mary she will be right back (in line 10), which Mary acknowledges in falsetto (in line 11). They use the falsetto register reciprocally. Daughter-L had been tending the fire for Elder-f. Now in line 12 Elder-f asks Mary to come over and take the place of Daughter-L at the stove. The elder woman's speech is in a modal voice unmarked for respect to the younger visitor. In line 13 Mary responds 
to the elder in falsetto voice that she is coming right away. Her husband adds to the feeling of urgency by telling her to go and tend the fire, seconding the request of the elder with a directive to Mary. Son-L offers that Mary take a chair on which to sit. In line 16 Mary responds to him affirmatively in the falsetto register. At this point she walks to the hearth with a chair and sits to tend the fire. Mary's husband begins a new topic by lamenting in line 18 that there will be no musicians at the party, which is not immediately taken up. He then upgrades his statement in line 20 by voicing Lencho, saying that Lencho also said they will not be able to have musicians at the party tomorrow. Son-L then agrees with Husband-M by saying "not even one." Then in line 22 Mary follows Son-L's response to make a joke, which is a rephrasing of Son-L in line 21. She says in modal voice "That's what I've been saying: Why don't you just call one of them?" Her joke seems to be risky here, and is not immediately successful. Failing to get the laugh immediately, Mary gazes at the Elder-f, who laughs and is then accompanied by all the others.

The joke in line 22 is based on a stereotype of musicians in the region, who are part of large brass bands. Soloists are nonexistent. In an extreme case it would be like hiring a tuba player as the soloist for your party. What is most relevant about line 22 here is that it is uttered in modal voice and not the falsetto voice that Mary had been using with both Son-L and Elder-f, although her statement obviously includes them. Helpful to understanding a shift like this is the framework of participation roles developed by Goffman (1974, 1981). The key to Mary's shift to modal voice is that she addresses this to her husband, which can be seen in the use of the second=person pronoun lò, which consultants have agreed selects her husband here. As her husband is her selected addressee she shifts to modal voice, but as she speaks loudly and is clearly building on the previous line of Son-L, she includes Son-L and Elder-f in a participant role that Goffman calls RATIFIED OVER-HEARER. The seriousness of the respect register would not make the joke appropriate in an overtly respectful persona. However, selecting her husband as her explicit addressee exists as a strategy for Mary to drop out of falsetto to deliver the punch line. The risk of the voice-register shift among these participant frameworks is apparent in the delay of laughter. Mary negotiates this moment with the assistance of Elder-f, whose laugh triggers the laughter of the others.

A similar shift between voice registers occurs a little later in the evening and is presented in example (14). Mary is still seated across from Elder-f and is tending the fire. She selects her husband as addressee, and in whispered voice asks him how much longer they would be staying; they also need to go to the store before it closes. Son-L has gone out to the patio and is not in the scene. Unlike the modal-voiced joke in the previous transcript, Mary uses a whisper register to frame these lines. Doing so she both frames the import of her words here, and importantly excludes Elder-f as an UNRATIFIED OVERHEARER. It is important to point out here that Mary is not whispering so that Elder-f does not hear her but rather that PUBLICALLY using the whisper register is the strategy that communicates to Elder-f that 
she is excluded. Mary's voice quality constructs the participant roles that relieve her of the responsibility to use falsetto voice.

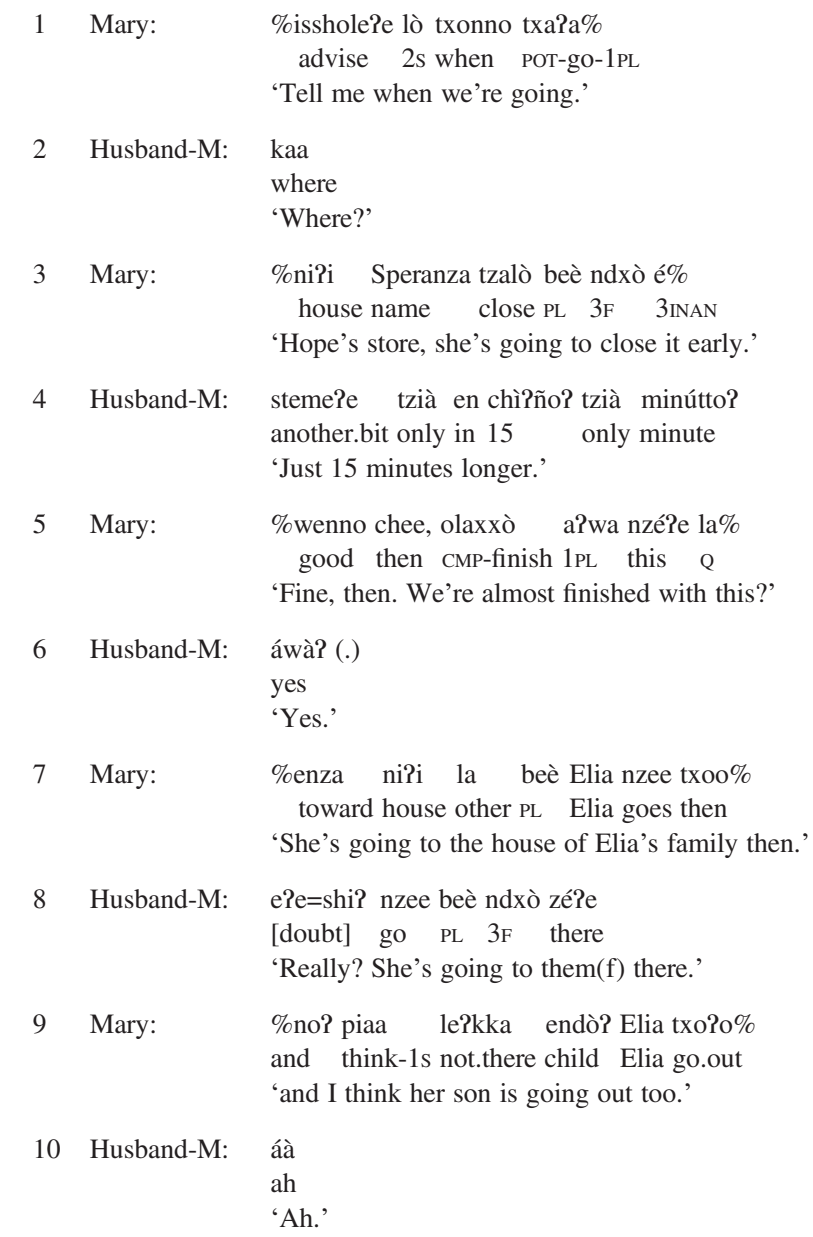

About ten seconds later Mary receives a request from Elder-f to hand her a bucket. The participation roles shift and Mary's addressee is now Elder-f. She shifts back into the falsetto register, once again showing respect for Elder-f and demonstrating her respectful self-image.

16 Elder-f: zéla lò bikkì teme?e kubetta ka?a la Maari want $2 \mathrm{~s}$ put little bucket here Q Mary 'Do you want to give me that little bucket, Mary?' 


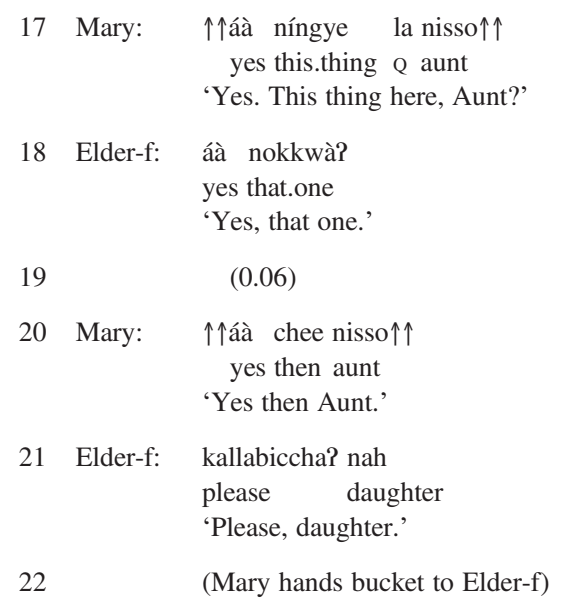

In this section I have considered the path of a single speaker as she shifts between three voice registers: falsetto, whisper, and modal. Using falsetto voice, Mary constructs an image of herself as a respectful speaker and pays tribute to the elder woman and her son whom Mary is visiting and to whom she shows respect. These registers also function creatively to shift the participation framework. In example (13) her shift to modal voice is licensed by selecting her husband as the ADDRESSEE, but the context and group laughter in the following turn shows that the other participants are selected as ratified OVERHEARERS. In example (14) she again selects her husband as addressee, framing her interaction with him in a public whisper to exclude the elder woman as an unratified overhearer. The voice registers form a system of contrasts between which an individual can navigate by creating a number of participation frameworks in interaction. Voices and roles are then both constraining on interactions and also a field for creativity in interactions.

These transcripts also make it clear that understanding gender roles is important in understanding the use of high pitch. Mary uses high-pitched voice more than her husband does, and in contexts where he does not. I can also attest to the fact that women are much more extreme in their use of high pitch, often approaching $500 \mathrm{~Hz}$ in their respectful utterances where most men rarely go above $300 \mathrm{~Hz}$, a difference that cannot be explained by reference to "natural" differences in the pitch range of men's and women's voices. This said it remains that at the time of this writing both women and men often use the respectful voice in Lachixío.

The Lachixío Zapotec case study presented here illustrates a set of voice registers for the Lachixío Zapotec language. However, the phenomena of voice registers seem to have a larger distribution in Mesoamerica. Global voice qualities are not a type of feature that is traditionally represented in dictionaries and grammars. 
My search revealed no published accounts that refer to respect registers indicated by voice quality in other Zapotec languages; however, respectful voice qualities were reported in numerous other Zapotec languages in response to a query I posed to speakers and scholars in 2009. Dave Riggs (p.c. 2009) reported that he has observed high-pitched voice in Amatlán Zapotec in the context of the town hall when a person addresses a town authority. Julie Hernandez (p.c. 2009) said that in San Juan Mixtepec women raise the pitch of their voice when speaking with respect to some people, but that it is not as marked as what goes on in Lachixío. A similar voice of respect is present in San Pablo Güilá: Aurea López Cruz (p.c. 2009) described it as a smooth voice used with important people, for religious matters, asking a woman's hand in marriage, and with religious and civil authorities. Elodia López Cruz (p.c. 2009) said the Rincón Zapotec area of the northern sierra of Oaxaca has a voice with similar qualities and use patterns as in Güilá. In each case the respectful voice register seems to be in declining use. I believe it was once much more widespread that we find it today - the register having fallen out of use again and again even as the languages continue to be spoken, resulting in the "spotty" distribution within Zapotec today. The presence of the respect register in several branches of Zapotec (Miahuatlán; Cisyautepecan, Tlacolula Valley, Rincón, and West Zapotec) raises the possibility that the discourse features be reconstructed to proto-Zapotec before its diversification with the expansion and collapse of the Monte Albán State 500BC-700CE. There is no model in Spanish speech that could be suggested to account for the distribution as a post-Columbian contact feature.

Interestingly, falsetto and other registers have also been described and reported in languages associated with other large Mesoamerican state societies: Mayan and Mexicano (Nahuatl). Such a distribution raises the question of whether patterns of voice registers are part of a larger Mesoamerican cultural area to which we can gain some access by looking at discourse features common across these distinct language stocks. The next section takes up this topic, considering published and unpublished reports of the use of voice qualities in defining social and participant roles in face-to-face interaction.

\section{VOICE REGISTERS: A DISCOURSE PATTERN OF THE MESOAMERICAN CULTURE AREA?}

Mesoamerica stands out as an area in both cultural practices (Kirchhoff 1952, Wolf 1957) and in linguistic features that pattern across language families like Zapotec, Mije-Zoque, Mayan, and Nahuatl. These families attest to language contact through pre-Columbian interaction spheres by the widespread presence of structural linguistic features and semantic features, such as loan translations (Campbell, Kaufman, \& Smith-Stark 1986). Discourse-level features like the voice registers discussed here may contribute to our understanding of Mesoamerica as a cultural and linguistic area with patterns shared across the distinct language stocks within its territory. 
Consider example (16), which demonstrates a high-pitched voice register used for respect, and a creaky voice register used for seeking commiseration among speakers of Tzeltal Maya of Chiapas (the state between Oaxaca and Guatemala). Brown and Levinson (1978:267), briefly discuss high pitch as a marker of politeness and of another voice style to mark commiseration in Tzeltal. Example (16) shows both of these contrastive voices patterning with the roles taken up by the speakers. ${ }^{8}$ Speaker P (about age 40) has come from her home in another village to visit her mother M (about age 60). This is the first visit she has made to her in many weeks. The two women assume complementary roles in the performance of a routine of seeking and providing commiseration. The daughter uses a highpitched voice to her mother who in turn speaks to the daughter in a voice that seeks commiseration, characterized by a voice with intonations falling repeatedly to creaky voice. The commiserating voice register is also widespread. As I mention above, I have heard it among Zapotec speakers of Oaxaca, and even speakers of nonstandard Spanish in rural regions (specifically among populations that have shifted from Zapotec). The two Tzeltal women in this transcript are talking about their chickens that get attacked by weasels at night. All of M's turns show low-pitched creaky voice, except for her final utterance, which reciprocates the high-pitched voice of the daughter and moves to close the sequence. While this example was recorded more than thirty-five years ago, the pattern is still current in Tenejapa (Penelope Brown, p.c. 2009).

(16) Tzeltal Maya, 1972, Tenejapa, Chiapas, Mexico
55 P: $\uparrow \uparrow j a ?$ ja? laj tey ya x-paxyaj-0 j-teb-uk it's.so it's.so QUOT there ICP ASP-walk.around-3A CL-a.bit-SUBJ
ya k-al ek' a $\uparrow$
ICP 3E-say too DEIC

'Yeah. I say to myself they (the chickens) walk around a bit there.'

$56 \mathrm{M}: \sim$ ja? te bil-uk tame ma?yuk x-lok'-ta y-al ti?awal-e $\sim$ it's.so ART what-SUBJ if none ASP-exit-TRS $\mathrm{S}_{\mathrm{i}}$ POS-son predator-CLI 'It'd be good if there weren't any predators to come out (and eat up the chickens).'

57 P: $\quad \uparrow \uparrow b i t ' i l x-a ? w-a l ! \uparrow \uparrow$ how ASP-2E-say

'What to say! ( $\rightarrow$ What can I say, I don't know if the predators can get in!)'

58 M: $\sim$ binti ya j-jol-in bol wax $=\sim$ what ICP 1e-head-TRS $\mathrm{n}$ stupid weasel

'The wretched weasel is a problem.'

59 P: $\quad \uparrow \uparrow j a r \uparrow \uparrow$

its.so

'That's so.'

60 M: =ay-0 a?w-utz'in-el yu?un ya k-a?y ek i EXIST-3A 2E-pester-NOM because ICP 1E-understand too DEIC

'There's trouble for you because of them (weasels) I understand too.' 
61 P: $\uparrow \uparrow m a$ wan tey-uk nax-ay-0 ek a $\uparrow$ NEG PT there-suBj just- EXIST-3A too DEIC

'I suppose there just isn't any there too! $\rightarrow$ Yes there certainly are troubles from weasels!)'

$62 \mathrm{M}: \quad \uparrow \uparrow$ tey $\uparrow \uparrow$

'There (they are)!'

63 P: $\uparrow \uparrow$ tey $\uparrow$

'There (they are)!'

Another reference to registers that are not segmentally marked comes from Laughlin (1975:28), who notes that in Tzotzil Maya, "polite speech" and "scolding speech" exist as speech categories, which have no particular structure associated with them.

Furbee $(1976,1988)$ refers to a high-pitched respectful voice for Tojolabal Maya of Chiapas. In describing "petition" as a speech genre of Tojolabal she writes, "the petitioner pitches his voice in a falsetto" (1988:44). This use appears to be parallel to the Zapotec cases where falsetto is used as the voice of prayer. As with Zapotec, the Tojolabal high-pitched voice is used as a marker of politeness: Furbee continues: "[b]ut falsetto speech is not confined to petition. Among the Tojolabal, falsetto is the voice of politeness and deference. Polite conversation carried on with persons of higher status would also be falsetto. Greetings and leavetaking will be delivered falsetto" (1988:44).

In another Mayan language, Quiché of Guatemala, there is some indirect evidence that high pitch exists there as well as a sign of respect or deference. Pye (1980, 1986) describes the avoidance of high pitch in speech directed toward children, arguing against the universality of high pitch in speech to infants. Previously, high pitch had been presented as a universal feature of "baby talk" registers (see Ferguson 1978). Pye demonstrates through acoustic analysis that speech to children for Quiché Maya speakers is characterized by lower pitch than speech to adults.

Furbee (1988:44) comments on Pye's observations "Pye (n.d.) has reported low pitch to be characteristic of the speech to Quiché mothers to their children, which would socially contradict the pattern of deferential speech, with its falsetto delivery. Mothers know their children better than they do anyone else and have no requirement for deference or respect in speech to them." In Mesoamerica, high-pitched voice to children may be socially inappropriate and thus is avoided since raising pitch is used for deference to adults. My own observations on speech to children in the Zapotec region of the Sierra Sur support this view as well. In twelve years working in Oaxaca I have never heard high-pitched voice directed toward infants or children in Zapotec the way it is in some European and American baby-talk registers. However, I have heard high-pitched voice being modeled for children showing them how to show respect.

While follow-up research needs to be conducted that specifically seeks answers to questions about contrastive meanings among such voice registers, Pye's work at 
least provides anecdotal evidence that whisper is used to children. Pye (1986:88) writes, "[t]he Quiché mothers frequently reduced their voice so much that it became a whisper." Penelope Brown (p.c. 2009) reports that whispered speech to children is also present in the Tzeltal Maya region; adults whisper to babies with soft imperatives. And we find another reference to breathy voice qualities with scolding or corrective functions in Tojolobal Maya. Louanna Furbee (p.c. 2009) conveyed that Tojolabal mothers "use a low, breathy voice when talking to children (especially directing or correcting them)." The function here is the same as in Lachixío: in directive, scolding, or corrective speech, a low pitched, breathy voice is used marking the register through the voice quality. Thus similar voice qualities have similar functions across an area spanning from Oaxaca to Guatemala.

I turn now to the area north of Zapotec country. Working with Nahuatl in central Mexico, Jane Hill notes voice qualities with similar functions to those described for Lachixío Zapotec. In her 2007 discussion paper, Hill describes her observations on high-pitched voice among Nahuatl speakers of the Malinche Volcano area of central Mexico. She said that many of the people of the area talked to her in "high, squeaky, falsetto" voices. People would say things like $\uparrow \uparrow$ Ximopanoltitzino, comadrita. $\uparrow \uparrow$ 'Come in comadre.' Here the utterance shows both the mark of the falsetto register and the title of comadre 'comother,' the respected ritual kin relation. Hill observed that the Mexicano-speaking women she worked with did not talk that way all the time by any means, but that they used falsetto a great deal for formulaic expressions of politeness. Hill also noted the use of a harsh, breathy voice, as I described for Lachixío, as the authoritative register to sometimes scold or command children or animals. She described the characteristic sound of shooing dogs away in the Malinche to show intense breathiness.

This description of multiple regions of Mexico and Guatemala where voice qualities are found to cue speech registers sketches the picture that these registers are not features unique to any particular language but rather to Mesoamerica as a culture area. Figure 2 shows the locations of the different languages where these voice registers have been reported.

\section{M P LIC A T ION S A N C ONCLUSION}

This study of voice qualities in Mesoamerica has revealed systems of speech registers in which voice qualities are enregistered through their co-occurrences with the participant roles taken up in speech situations. Demonstrating the importance of bringing the concept of linguistic register into dialog with the concept of prosodic register, I describe the voice registers of the Zapotec speaking region of Lachixío where falsetto phonation shows respect, breathy phonation shows authority, creaky phonation seeks commiseration, and whisper phonation marks urgency. More than just marking presupposed social relations, I show that these voice registers are used creatively as strategies with which speakers can navigate 


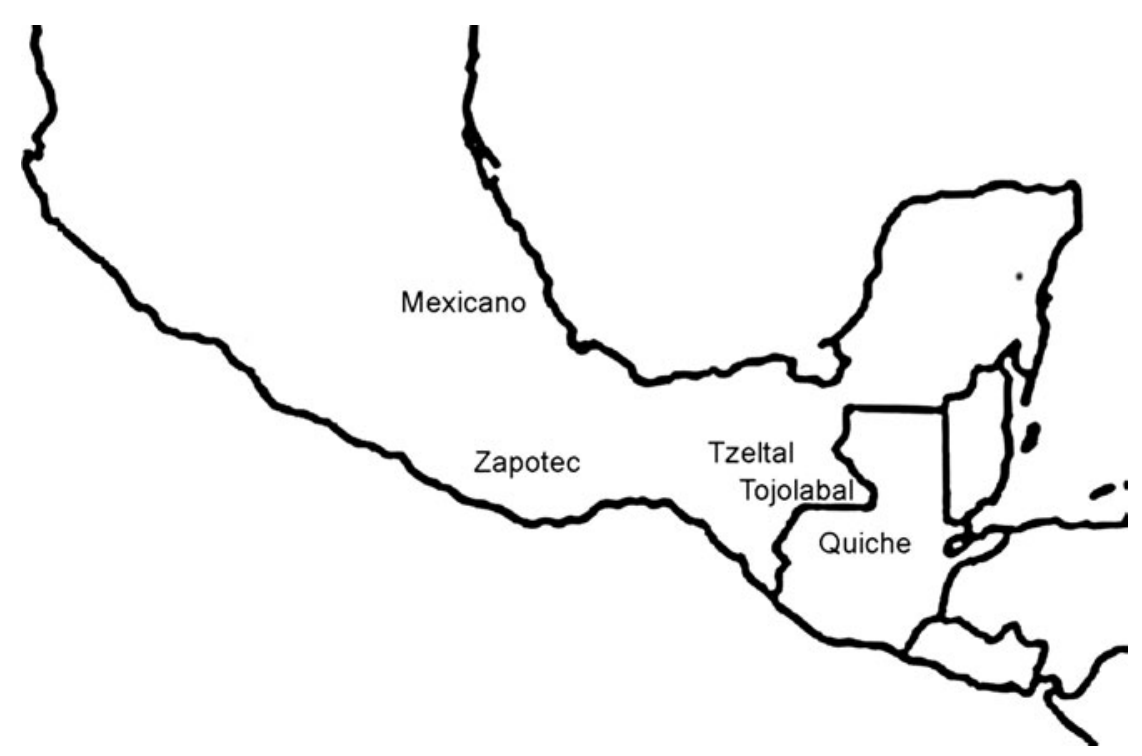

FIGURE 2. Locations of languages where voice registers have been reported in Mesoamerica.

through the social roles of dialogue, assigning participation roles like ratified overhearer to include participants and unratified overhearer to exclude participants.

Zapotec speakers use pitch and voice qualities at key points of dialogue to frame speech in ways that creates or acknowledges the social roles of those copresent in face-to-face interaction. These devices importantly display an individual speaker's communicative competence and self image. Features of voice quality at key points of dialogue are "contextualization cues" as described by Gumperz (1992:232), because they function relationally for the purpose of framing an utterance. The data from Lachixío show how prosody and voice qualities as contextualizing layers of speech can undergo processes of enregisterment or formalization in which they become iconic of social roles and situations.

In the investigation of linguistic registers, this study of voice registers highlights several contrasts with studies of lexical registers. First, where lexical registers are often accessible through written materials, voice qualities are notably absent from written representations, unless particular attention has been paid to such features in the entextualization process. Second, voice qualities are generally nonreferential and less present to consciousness for native speaker consultants and for researchers than referential lexical material. This second feature is interesting, considering the suggestive evidence that contrasting voice registers with the same functions as those in Lachixío are present in numerous language families of Mesoamerica.

This article is the first to bring together data from three unrelated Mesoamerican language families that show common functions for voice registers: Zapotecan, 
Nahuatl, and Mayan. Since few linguists have attended to discourse-level uses of voice quality, numerous field trips would have to be dedicated to fleshing out the description of voice qualities across Mesoamerica to allow for stronger conclusions. However, there is enough suggestive evidence that registers, such as those I describe here for Lachixío, are used beyond the region of Lachixío within Mesoamerica.

It is not new to see that linguistic registers can have some relationship to language-contact situations. Relationships between standard and nonstandard languages, situations of diglossia, and high registers all show that the historical social relationships of people in contact can come to be enregistered in a language. Lexical registers are often shown to have some discernable relationship to a source for the vocabulary. Errington (1988) points out that Krama, the high speech level of Javanese, contains much Indonesian vocabulary. The magical incantations of the Trobriand Islands show vocabulary from languages of neighboring islands (Senft 1997). Hill and Hill (1986) describe the use of Spanish in Mexicano as a "power code" register used by older men. Similar patterns can also be seen in how legal and medical professional registers draw vocabulary from Latin and Greek. The common thread among these examples is that lexical materials from different languages have been enregistered as unequal within a language. In a heteroglossic language topology, the vocabulary of one language functions as a high or restricted register in another.

At first glance the situation with voice registers stands out as qualitatively different. Voice qualities in the language-contact situation of the Mesoamerican area show a similar set of contrasts across languages of three unrelated stocks. ${ }^{10}$ Such an unsourced "portability" for voice quality makes it a useful linguistic tool for conducting cultural analysis in multilingual societies. It also raises numerous questions for future investigation. For a feature to be indicative of a linguistic area it must be shown that an areal feature that occurs within the proposed area occurs in lower frequencies outside its boundaries (Thomason 2001:104). Uto-Aztecan provides an excellent test case because there are no reports of respectful falsetto voice in Uto-Aztecan languages of the US Southwest, but there are in the Uto-Aztecan Nahuatl spoken within Mesoamerica. In order to demonstrate this, we would need to see more primary research on discourse functions of voice qualities within the Mesoamerican area and with indigenous languages of the regions to the north and south.

Attuning to the use of voice qualities in social interactions, it quickly becomes apparent that in any language and region there is systematic distribution of the voices an individual can take on in dialogue. While the voice qualities I describe in Mesoamerica may stand out to readers as striking, it is becoming clear that we can find voice phenomena occurring in every language. A program of research that investigates voice qualities in comparative perspective is necessary and long overdue. For years it has been suggested that there is a naturalness of meanings associating pitch and voice qualities (Brown \& Levinson 1987, Gussenhoven 
1999, 2002, Ohala 1994). Brown and Levinson (1987:268) suggest that the correlation of prosodic features with social contexts may follow from natural associations, such as that high pitch associated with children leads to the use of high pitch by adults to function as humbling. Ohala 1994 argues for a "frequency code" that underlies a sound symbolism grounded in a claimed biological universal relating the size of an organism to the frequency of its voice: higher pitches, he claims, show submission and lower pitches dominance. Gussenhoven (1999, 2002) expands the number of biological codes to include an "effort code" in which high pitch can take its value as a sign of the greater effort it takes to articulate it, thus functioning for "insistence," or "emphasis." In contrast to the idea that prosodies have "natural meanings," there have been recent arguments based in ethnography that explicate cultural motivations for voice qualities as sign vehicles (Mendoza-Denton 2008, Podesva 2007). When the rich descriptions of ethnographic accounts are brought into dialogue with claims of universal biological codes, the biological-code explanations may seem to rely on ad hoc reasoning to explain away exceptions to the code as somehow "unnatural." There is potential for productive dialogue here; however, at this point few ethnographic accounts explicitly engage these claims of the functional universality or naturalness of voice qualities. Rather than assuming underlying biological codes for voice qualities and then selecting cases of speech forms to support these claims, we would do better to use ethnography and prosodic description together to make explicit the orders of semiotic process that mediate the patterned co-occurrences of voice qualities with speech contexts and social functions. In other words, we should focus on the processes of enregisterment through which voice qualities come to take on social functions. There is great potential for this research theme and with continued attention to social features of voice qualities we can develop a cross-cultural study of the voice.

\section{N O T E S}

*This article has benefited from the assistance of Lachixío Zapotec speakers, Pedro Martínez García for his videography; Angelica Hernández García, María Morales, and Daniel Hernández Morgan for their help transcribing and characterizing the social actions and participation frameworks achieved through shifting voices; and the late Fabiano Hernández García for his original storytelling and help with transcription. This article is dedicated to the memory of Fabiano, who died in October 2009. Some of the analysis here was first developed in my dissertation for which I acknowledge the support of my advisors: Sarah Thomason, Bruce Mannheim, Robin Queen, and Joyce Marcus. I am grateful for the thoughtful comments and criticisms of Penelope Brown, Nick Enfield, Jane Hill, Gertie Hoymann, Judith Irvine, Barbara Johnstone, Daniel Lefkowitz, Stephen Levinson, Gilles Polian, Gunter Senft, Kelly Sicoli, Audra Starcheus, Tanya Stivers, Deborah Tannen, Anthony Webster, Matthew Wolfgram, and two anonymous reviewers. Their suggestions have been instrumental in improving this work. Any shortcomings that remain are my sole responsibility.

${ }^{1}$ Sapir also includes a fifth level that he called "style," which I have left out here, partly because it seems to be a different logical type of entity than any of his other levels, since each of those levels can contribute to defining style. 


\section{SHIFTING VOICES WITH PARTICIPANT ROLES}

${ }^{2} \mathrm{I}$ am developing this theme in a separate paper that addresses the relationship of prosody to consciousness and the reproduction of culture categories, icons, and routines in socialization practices.

${ }^{3}$ The creaky voice that seeks commiseration is generally a feature in woman's speech, and for this feature I have not been fortunate to get audio or video examples. I have, however, observed its use, and speakers have characterized its functions in conversations about the language.

${ }^{4}$ I am developing elsewhere relationships of pitch to qualities of experiences like "effort" and "mass."

${ }^{5} \mathrm{All}$ of the names of people in the transcribed data have been changed.

${ }^{6}$ See the appendix for transcription conventions. The following abbreviations are used in the glosses: 1E: first person ergative, 1PL: first person plural, 1PLX: first person plural exclusive, 1s: first person singular, 2E: second person ergative, 2s: second person singular, 3A: third person absolutive, 3AO: third person result of active agent, 3DIs: distal place reference, 3F: third person singular feminine, 3I/E: third person infant and elder, 3INAN: third person inanimate, 3M: third person singular masculine, 3REs: third person respect/distal, ASP: neutral aspect, CL: classifier, CLI: clause-final clitic, CMP: completive aspect, COMP: complementizer, CONJ: conjunction, DEIC: deictic, DEF: definite article, DIM: diminutive, EXC: exclamative enclitic, HAB: habitual aspect, ICP: incompletive, NEG: negation, PL: plural, POS: possessive, POT: potential mood, PT: particle, Q: polar question enclitic, QUOT: quotative, REL: relative pronoun, STA: stative aspect, sUBJ: subjunctive, $\mathrm{TRS}_{\mathrm{i}}$ : transitivizer of intransitive root, $\mathrm{TRS}_{\mathrm{n}}$ : transitivizer of noun root,

${ }^{7} \mathrm{~A}$ consequence of the necessary specification of a turn for the presence or absence of respect is that greetings, farewells, and other utterances are rarely issued in the plural. For example, in (1) and (2) Flavio addresses the mother and daughter separately rather than use a plural form of address. This constraint was also noticed by Caton (1986) in greetings in highland Yemen. In Lachixío the necessity to show the proper level of respect to each individual can result in persons excusing themselves from a dining table of a large party by an extraordinary number of one-to-one leave-takings.

${ }^{8}$ Thanks to Penelope Brown for providing me with the transcript, translation, and audio recording for this segment of Tzeltal conversation.

${ }^{9}$ This avoidance is parallel to the case of Samoa described in Ochs \& Schieffelin 1984. Ochs and Schieffelin challenge the universality of another claimed feature of the so-called "baby talk" register-that of lexical and syntactic simplification. In Samoa utterances to children are not lexically or syntactically simplified because simplification would be seen as accommodating the speech to the addressee. In the strict age-rank system of Samoan chiefdom society, accommodation would be the obligation of the lower-ranking interlocutor, thus performed by a lower-ranked speaker to a higher-ranked addressee. It would not be appropriate for a higher-ranked individual to simplify speech for a lowerranked child.

${ }^{10}$ This is also the case with the enregisterment of prosody in Wolof (Irvine 1974). Both noble and griot use the same set of prosodic contrasts in the same way to create relative status differences within their caste.

\section{R E F E R E N C E S}

Agha, Asif (1998). Stereotypes and registers of honorific language. Language in Society 27:151-93. (2004). Registers of language. In Alessandro Duranti (ed.), A companion to linguistic anthropology, 23-45. Malden: Blackwell. (2005). Voice, footing, enregisterment. Journal of Linguistic Anthropology 15(1):38-59. (2007). Language and social relations. Cambridge: Cambridge University Press.

Atkinson, Dwight, \& Biber, Douglas (1994). Register: A review of empirical research. In Douglas Biber \& Edward Finegan (eds.), Sociolinguistic perspectives on register, 351-85. Oxford: Oxford University Press.

Biber, Douglas, \& Hared, Mohamed (1994). Linguistic correlates of the transition to literacy in Somali: Language adaptation in six press registers. In Douglas Biber \& Edward Finegan (eds.), Sociolinguistic perspectives on register, 182-216. Oxford: Oxford University Press.

Bourdieu, Pierre (1991). Language and symbolic power. Oxford: Basil Blackwell. 


\section{MARK SICOLI}

Brody, Jill (1986). Repetition as a rhetorical and conversational device in Tojolabal (Mayan). International Journal of American Linguistics 52(3):255-74.

(1994). Multiple repetitions in Tojolobal conversation. In Barbara Johnstone (ed.), Repetition in discourse: Interdisciplinary perspectives, vol. 2, 3-14. New York: Ablex.

Brown, Penelope, \& Levinson, Stephen C. (1987). Politeness: Some universals in language usage. Cambridge: Cambridge University Press.

— Zapotec conversation. Paper presented at the summer meeting of the Society for the Study of the Indigenous Languages of the Americas, Berkeley, California.

Brown, Roger, \& Gilman, Albert (1960). The pronouns of power and solidarity. In Thomas A. Sebeok (ed.), Style in language, 253-76. Cambridge, MA: MIT Press.

Campbell, Lyle; Kaufman, Terrence; \& Smith-Stark, Thomas C. (1986). Meso-America as a linguistic area. Language 62:530-70.

Catford, J. C. (1964). Phonation types: The classification of some laryngeal components of speech production. In David Abercrombie, D. B. Fry, P. A. D. MacCarthy, N. C. Scott, \& J. L. M Trim (eds.), In honour of Daniel Jones, 26-37. London: Longman.

Caton, Steven C. (1986). Salaam tahiiyah: Greetings from the highlands of Yemen. American Ethnologist 13:290-308.

Couper-Kuhlen, Elisabeth (2003). Intonation and discourse: Current views from within. In Deborah Schiffrin, Deborah Tannen, \& Heidi E. Hamilton (eds.), The handbook of discourse analysis. Oxford: Blackwell.

Eckert, Penelope, \& McConnell-Ginet, Sally (2003). Language and gender. Cambridge: Cambridge University Press.

Errington, Joseph (1988). Structure and style in Javanese: A semiotic view of linguistic etiquette. Philadelphia: University of Pennsylvania.

Ferguson, Charles (1978). Introduction. In Joseph Greenberg (ed.), Universals of human language, vol. 3: Word structure, 1-6. Palo Alto, CA: Stanford University Press.

Furbee, Louanna (1976). The correct language, Tojolabal: A grammar with ethnographic notes. New York: Garland.

(1988). To ask one holy thing: Petition as a Tojolabal speech genre. In Jill Brody \& John S. Thomas (eds.), The Tojolabal Maya: Ethnographic and linguistic approaches, 39-53. Baton Rouge: Louisiana State University.

Gaudio, Rudolf P. (1994). Properties in the speech of gay and straight men. American Speech 69:30-57.

Goffman, Erving (1974). Frame analysis: An essay on the organization of experience. New York: Harper \& Row.

— (1981). Footing. In Erving Goffman, Forms of talk, 124-59. Philadelphia: University of Pennsylvania Press.

Gordon, Matthew, \& Ladefoged, Peter (2001). Phonation types: A cross-linguistic overview. Journal of Phonetics 29:383-406.

Graddol, David, \& Swann, Joan (1989). Gender voices. Oxford: Blackwell.

Gumperz, John J. (1992). Contextualization and understanding. In Alessandro Duranti \& Charles Goodwin (eds.), Rethinking context: Language as an interactive phenomenon, 229-52. New York: Cambridge University Press.

Gussenhoven, Carlos. (1999). Discreteness and gradience in intonational contrasts. Language and Speech 42(2-3):283-305.

(2002). Why question intonations rise and why they sometimes fall. In Michael Hoey \& N. Scott (eds.), Questions: Multiple perspectives on a common phenomenon. Liverpool: University of Liverpool Press.

Hall, Kira (1995). Lip service on the fantasy line. In Kira Hall \& Mary Bucholtz (eds.), Gender articulated: Language and the socially constructed self, 183-216. New York: Routledge. 


\section{SHIFTING VOICES WITH PARTICIPANT ROLES}

Haviland, John B. (1990). We want to borrow your mouth: Tzotzil marital squabbles. Anthropological Linguistics 30(3-4):395-447.

Hay, Jennifer, \& Drager, Katie (2007). Sociophonetics. Annual Review of Anthropology 36:89-103.

Hill, Jane H. (1995). The voices of Don Gabriel: Responsibility and moral grounds in a modern Mexicano narrative. In Dennis Tedlock \& Bruce Mannheim (eds.), The dialogic emergence of culture, 97-147. Urbana: University of Illinois Press.

(2007). Discussion: Phonation, voice, and style. Paper presented at the 106th annual meeting of the American Anthropological Association, Washington, DC.

— \& Hill, Kenneth C. (1986). Speaking Mexicano. Tucson: University of Arizona Press.

Hymes, Dell (1974). Ways of speaking. In Richard Bauman \& Joel Sherzer (eds.), Explorations in the ethnography of speaking, 433-51. New York: Cambridge University Press.

(1983). Sapir, competence, voices. In Charles Fillmore, Daniel Kempler, \& William S.-Y. Wang (eds.), Individual differences in language ability and language behavior, 33-45. New York: Academic Press.

Irvine, Judith T. (1974). Strategies of status manipulation in Wolof greetings. In Richard Bauman \& Joel Sherzer (eds.), Explorations in the ethnography of speaking, 167-91. New York: Cambridge University Press.

- (1990). Registering affect: Heteroglossia in the linguistic expression of emotion. In Catherine. A. Lutz \& Lila Abu-Lughod (eds.), Language and the politics of emotion, 121-61. New York: Cambridge University Press.

(1998). Ideologies of honorific language. In Bambi B. Schieffelin, Kathryn A. Woolard, \& Paul V. Kroskrity (eds.), Language ideologies: Practice and theory, 51-67. New York: Oxford University Press.

Kim, Yong-Jin, \& Biber, Douglas (1994). A corpus-based analysis of register variation in Korean. In Douglas Biber \& Edward Finegan (eds.), Sociolinguistic perspectives on register, 157-81. Oxford: Oxford University Press.

Kirchhoff, Paul (1952). Mesoamerica. In Sol Tax (ed.), Heritage of conquest, 17-30. Glencoe: Free Press. Ladd, D. Robert. (2008). Intonational phonology. Cambridge: Cambridge University Press.

Lakoff, Robin (1975). Language and woman's place. New York: Harper \& Row.

Laughlin, Robert M. (1975). Great Tzotzil dictionary of San Lorenzo Zinacantán. Washington, DC: Smithsonian Institution Press.

Laver, John (1968). Voice quality and indexical information. British Journal of Disorders of Communication 3:43-54.

- (1980). The phonetic description of voice quality. Cambridge: Cambridge University Press.

(1991). The gift of speech: Papers in the analysis of speech and voice. Edinburgh: Edinburgh University Press.

Lefkowitz, Daniel, \& Sicoli, Mark (2007). Creaky voice: Constructions of gender and authority in American English conversation. Paper presented at the 106th annual meeting of the American Anthropological Association, Washington, DC.

Mandelbaum, David G. (ed.) (1949). Selected writings of Edward Sapir in language, culture, and personality. Berkeley: University of California Press.

Mannheim, Bruce (2001). Iconicity. In Alessandro Duranti (ed.), Key terms in language and culture, 102-5. Malden, MA: Blackwell.

McLemore, Cynthia (1991). The pragmatic interpretation of English intonation: Sorority speech. Austin: University of Texas, Austin dissertation.

Mendoza-Denton, Norma (1997). Chicana/Mexicana identity and linguistic variation: An ethnographic and sociolinguistic study of gang affiliation in an urban high school. Palo Alto, CA: Stanford University dissertation.

(1999). Turn-initial no: Collaborative opposition among Latina adolescents. In Mary Bucholtz, A. C. Liang, \& Laurel A. Sutton (eds.), Reinventing identities, 273-92. New York: Oxford University Press. 


\title{
MARK SICOLI
}

(2008) Homegirls: Language and cultural practice among Latina youth gangs. Malden: WileyBlackwell.

Ochs, Elinor, \& Schieffelin, Bambi (1984). Language acquisition and socialization: Three developmental stories and their implications. In Richard Shweder \& Robert LeVine (eds.), Culture theory: Essays on mind, self, and emotion, 276-320. Cambridge: Cambridge University Press.

Ohala, John (1994). The frequency code underlies the sound symbolic use of voice pitch. In Leanne Hinton, Johanna Nichols, \& John J. Ohala (eds.), Sound symbolism, 325-47. Cambridge: Cambridge University Press.

Paulston, Christina B. (1976). Pronouns of address in Swedish: Social class semantics and a changing system. Language in Society 5:359-86.

Peirce, Charles Sanders ([1902] 1955) Logic as semiotic. In Justus Buchler (ed.), Philosophical writings of Peirce, 98-115. New York: Dover.

Persons, Janet A. (1997). High pitch as a mark of respect in Lachixío Zapotec. Working papers of the Summer Institute of Linguistics 41:59-60.

Podesva, Robert J. (2006). Phonetic detail in sociolinguistic variation: Its linguistic significance and role in the construction of social meaning. Palo Alto, CA: Stanford University dissertation.

(2007). Phonation type as a stylistic variable: The use of falsetto in constructing a persona. Journal of Sociolinguistics 11(4):478-504.

Pye, Clifton (1980). The acquisition of grammatical morphemes in Quiché Mayan. Pittsburgh, PA: University of Pittsburgh dissertation.

(1986). Quiché Mayan speech to children. Journal of Child Language 13:85-100.

Sapir, Edward (1927). Speech as a personality trait. American Journal of Sociology 32:892-905. Reprinted in David G. Mandelbaum (ed.), Selected writings of Edward Sapir in language, culture, and personality, 533-43. Berkeley: University of California Press, 1949.

Searle, John R. (1976). A classification of illocutionary acts. Language in Society 5:1-23.

Senft, Gunter (1997). Magical conversation on the Trobriand Islands. Anthropos 92:369-91.

Sicoli, Mark A. (2007). Tono: A linguistic ethnography of tone and voice in a Zapotec region. Ann Arbor: University of Michigan dissertation.

Silverstein, Michael (1981). The limits of awareness. Sociolinguistic Working Papers 84:1-10. Austin, TX: Southwest Educational Development Laboratory.

Starr, Rebecca L. (2007). Sweet voice: The role of voice quality in a Japanese feminine style. Paper presented at the 106th annual meeting of the American Anthropological Association, Washington, DC.

Tannen, Deborah (1989). Talking voices. New York: Cambridge University Press.

- (1993). Framing in discourse. New York: Oxford University Press.

(2010). Abduction, dialogicality and prior text: The taking on of voices in conversational discourse. Plenary address presented at the 84th annual meeting of the Linguistic Society of America, Baltimore, MD.

Tedlock, Dennis (1983). The spoken word and the work of interpretation. Philadelphia: University of Pennsylvania Press.

Thomason, Sarah G. (2001). Language contact: An introduction. Washington DC: Georgetown University Press.

Wolf, Eric R. (1957). Closed corporate peasant communities in Mesoamerica and Central Java. Southwestern Journal of Anthropology 13(1):1-18.

\section{A P P E N D I X: T R A N S C R I P T I O N C O N VEN T I O N S}

Registers are bracketed with symbols marking the onset and offset of the feature.

\author{
$\uparrow \quad$ high pitch \\ $\uparrow \uparrow \quad$ falsetto voice
}


$\downarrow \quad$ low pitch

\# breathy voice

$\%$ whisper voice

creaky voice

low tone

- high tone

/tx/ voiceless retroflex affricate

/x/ voiceless retroflex fricative

(Received 14 May 2009; revision received 13 November 2009; accepted 20 November 2009; final revision received 25 March 2010) 